\section{A molecular outlook review on how coffee and oats can help redefine the way we take care of our health}

\author{
Aurora de Jesus Garza-Juarez, Zuca G-Buentello, Jose Francisco \\ Islas, Juan Luis Delgado-Gallegos*
}

Universidad Autónoma de Nuevo León, Facultad de Medicina, Departamento de Bioquímica y Medicina Molecular, San Nicolás de los Garza, Ave. Francisco I. Madero y Dr. Aguirre Pequeño Col. Mitras Centro, Nuevo León, 64460 México. +52 (81) 832-94173

\begin{abstract}
Address for correspondence:
Juan Luis Delgado-Gallegos, M.D. Assistant Professor of Biochemistry and Molecular Medicine. Universidad Autónoma de Nuevo León, College of Medicine, Monterrey, México. Contact: juan_luisdg@hotmail.com
\end{abstract}

How to cite this article: Juarez AJG, Buentello ZG, Islas JF, Gallegos JLD. A molecular outlook review on how coffee and oats can help redefine the way we take care of our health. G Med Sci. 2021; 2(3): 053-064.

https://www.doi.org/10.46766/thegms.nufosci.21062404

Copyright: @ 2021 Aurora de Jesus Garza-Juarez, Zuca G-Buentello, Jose Francisco Islas, Juan Luis DelgadoGallegos. This is an Open Access article distributed under the Creative Commons Attribution License, which permits unrestricted use, distribution, and reproduction in any medium, provided the original work is properly cited.

\begin{abstract}
Background: Chronic degenerative diseases like obesity, metabolic syndrome, diabetes, fatty liver, have gained high prevalence in the world, due to sedentarism, improper nutritional habits as well as alcohol and tobacco consumption. Studies have shown that regular consumption of breakfast leads to a wide range of benefits, especially for the liver. The liver is a key organ for metabolic homeostasis regulating and governing energy metabolism, mostly providing nutrients for reabsorption. Benefits of a nutrimental quality breakfast seem to help lower body mass index, prevent metabolic diseases, and overall improve quality of life. Unfortunately, these include either high cholesterol or high-sugar foods including cold cuts, bread, eggs, and sugary beverages. Also, much of the population's work schedule relates to long hours and high-level of stress, therefore malnutrition, and inadequate eating schedules are common.
\end{abstract}

Methods: A systematic search was conducted using, PubMed Central, Science Direct, MEDLINE, Google scholar, to identify all studies regarding coffee and oats, published in English or Spanish, spanning from January 2020 to March 2021, using search terms (coffee OR oats) AND (bioactive OR compounds) AND (OR health benefits) AND (diet OR supplement).

Conclusions: The consumption of coffee and cereals, and it's bioactive characteristics have been linked to reduce oxidative stress and reactive oxygen species, inhibit lipid peroxidation, and improve mitochondrial function. A decrease in enzyme elevations, reduce risk of fatty liver disease, cirrhosis, and non-alcoholic steatohepatitis, improves cardiovascular health as well as plays critical roles in anticancer defence through the adaptive immune system.

Keywords: Coffee, cereals, molecular outlook review

\section{Introduction}

A common statement is that breakfast is the most important meal of the day, and studies have shown that regular consumption of a balanced breakfast does lead to a wide range of benefits. Benefits of a substantial quality breakfast seem to help lower body mass index, assist in higher cognitive performance, and overall improve quality of life [1]. Yet, to fully enjoy the benefits of breakfast, it is important to observe the quality and balance of the nutritional contribution especially for the liver, since micro and macronutrients are essential for its function [2]. Arguably food with a low glycemic index, such as
Oatmeal made from steel cut or rolled outs, associates with maintenance of energy levels, and improving both glucose and lipid metabolism [3]. On the other hand, much of the world population drinks "black gold" otherwise known as coffee and as we will see, we can make an association of coffee as a healthy option in decreasing liver diseases by acting over enzymes and antioxidants [4]. Approximately a third of Americans eat breakfast daily. Unfortunately, they include either high cholesterol or high-sugar foods including bread, starches, cold cuts, and sugary beverages, which are overall not good for the liver [5]. Also, much of the population's work schedule relates to long hours and high-levels of stress, and not to 
mention the rise in the cost of living under the stress of the COVID-19 pandemic [6-8]. Under these conditions' malnutrition, alcohol (or substance) consumption, and inadequate eating schedules are common. Therefore, it is clear that we need to develop a plan of action to combat these negative effects. One simple way to advance our state of health is to help develop better nutritional habits such as developing healthy, economical, accessible, and easy to prepare meals to prevent or reduce the progression of chronic degenerative diseases. All common and affordable components eaten in one way or another throughout the American continent, generally makes them easy to adopt when health professionals suggest their consumption [9].

\subsection{Non-communicable diseases}

Chronic degenerative diseases have gained high prevalence in the world as sedentarism, alcohol and tobacco consumption, improper nutritional habits, and obesity have become more common [10]. Diseases like metabolic syndrome, diabetes, and fatty liver, target many organs such as the heart, the guts, and the liver, which, when untreated can become more susceptible to develop unwanted comorbidities $[8,9]$. Here, there is an interesting case to be made for the liver, as not only these behaviors lead to an increase in degenerative diseases which end up affecting the liver, but also the pharmacological reagents used to treat these diseases are typically processed in the liver, hence, the combined effect becomes a disastrous scenario [3,12]. Out of the top 20 chronic degenerative diseases, there are 2 major diseases affecting the liver: cirrhosis, which holds the $11^{\text {th }}$ place and liver cancer which sits at the $16^{\text {th }}$ place [13]. More remarkably, all chronic liver diseases account for an estimate of 2 million deaths worldwide, and with the added complications of cirrhosis and liver cancer, they total just over $3.5 \%$ of deaths worldwide [3]. Interestingly, when we break down these numbers by gender, results show that women commonly present higher levels of acute liver failure, autoimmune hepatitis, and benign liver lesions, while men have a 2-fold higher likelihood of dying from complications and chronic forms of these pathologies, which puts into perspective the exacerbated effects of the behaviours earlier mentioned [16].

Other underlying etiologies implicated in liver diseases include viral hepatitis B \& C, non-alcoholic steatohepatitis, certain autoimmune diseases, and as mentioned earlier drugs and certain pharmaceuticals, typically used to fight these diseases, can cause liver or kidney damage. Pharmacological agents through their metabolism produce oxidative stress and inflammation resulting overtime in organ fibrosis $[17,18]$. Organ fibrosis begins as an imbalance between the synthesis and degradation of the extracellular matrix (ECM), inducing remodeling and loss of key components which further exacerbates to fibrosis, as the structural integrity of the ECM becomes compromised [19]. Because of this pathology, the liver presents scars, loss of parenchymal architecture, disruption of hepatic blood flow which ultimately leading to organ failure. It is important to note; the liver is a key organ for metabolic homeostasis regulating and governing energy metabolism, mostly because of the hepatic portal vein, which is the gateway out of the digestive system, providing nutrients for reabsorption $[2,20]$.

\subsection{Coffee}

For the past two decades, coffee consumption has been a staple in the decrease risk of liver diseases. Particularly, linked to the decrease of liver-associate enzymes AST/ ALT, alcoholic liver disease, and reduce risk of fibrosis in steatohepatitis. In recent years, studies have shown a relationship of coffee consumption to increase plasma glutathione, lessening in cirrhosis damage, and cut in the overall risk of hepatocarcinoma cancer $[21,22]$.

Liver fibrosis a process highly regulated by transforming growth factor beta (TGF-b), makes hepatic stellar cells (HSC) differentiate into myofibroblasts inducing overexpression of ECM. Interestingly this leads also to high expression of CTGF and in turn inducing a vicious cycle of profibrotic cytokines [23]. Compounds found in coffee are known to have a reducing effect over fibrosis by restoring redox balance, thereby inactivating the mechanisms that induce HSC differentiation, particularly caffeine blocks smooth muscle alpha and MMP2 and $9[18,24]$. In addition, the overall protective effects of coffee are seen even in the mitochondria as HSP70, an innate immune defense factor is activated, also DJ-1 autophagy factor and redox-sensing protein (ROS scavenger) activates inducing glutathione synthesis [4, 25]. Moreover, nicotinic acid induces apoptosis of differentiating HSC, which further helps with ECM remodeling reduction of collagen I and attenuation of the oxidative process [26]. Reduction of the oxidative process at the DNA is critical to help prevent mutations, as mentioned coffee consumptions was associated with this, however, till now this was studied in the context of viral hepatitis $\mathrm{C}(\mathrm{HCV})$. When coffee consumption was tested, it showed direct correlation with reduce DNA damage and most importantly procollagen III reduction, further permitting stabilization of the ECM [4].

Chemically, coffee can slightly differ within varieties and cultivation conditions. There are several key bioactive components, which concentrations are likely to vary, many of these key compounds derive from terpenes including caffeine, caffeic acid, cafestol, theobromine, theophyline, chlorogenic acid, kahweol, trigonelline, melanoidins, nicotinic acid, and other phenolics [12, 15]. Principal structures of Coffee-derived compounds can be found in Figure 1.

\subsection{Oats}

Whole grain cereals such as Oats are an important staple of the north American breakfast, yet they are 
typically resolved with high sugar supplementation. This supplementation converts them into having a high glycemic index. Meanwhile, Oats, either steel cut or rolled are food with low glycemic index and have been typically been associated with insulin and cholesterol lowering effects, cancer reduction, and even weight control [27].

Benefits of consuming whole grain cereals in modern times can be traced back to the Battle Creek Sanitarium and to J. H. Kellogg a physician and nutritionist who believed that the intestinal flora could be altered and alleviated from diseases depending on nutrition. Particularly, Kellogg denoted that on the liver the effects of alcohol and stress could deteriorate it, yet through the consumption of whole grains function was improved [28].

Nowadays, these benefits have directly been linked to the molecular components pertained within the grains. Moreover, fibrosis which can occur due to alcohol consumption or due to problems with weight and sugar control, has been shown to be mediated by the consumption of cereals as the phytochemicals found can directly interact with the bacteria present and mediate ROS attacks and production, as well as other secondary reactions and metabolites [29]. Compounds such as phenolics and avenanthramides found in cereals serve as antioxidants, in addition b-glucans can help directly in weigh and sugar control. The mechanisms of action of these compounds are further detailed within.

Since pre-Hispanic times north-America has been associated with many cereal crops [30]. Today's influence of the industry has made widely available these high sugary cereals, although we will not state that they are solely responsible for the high levels of chronic liver degenerative diseases, we could argue that they have predisposed to an extent these conditions. But there is a silver lining having been exposed to cereals, introducing less processed and more defined cereals to a breakfast regimen would seem to be an option with potential to have high acceptance [31].

\subsection{A molecular view into Coffee and Oats most effective compounds}

\section{Caffeine}

Most coffee beans contain to $10-12 \mathrm{mg} / \mathrm{g}$ of caffeine. It is one of the most recognized of all the components of coffee; it increases metabolic rate, energy expenditure, lipid oxidation, and thermogenic activities as in the prevention of cardiovascular, metabolic and neurodegenerative diseases [32]. Caffeine and adenosine have very similar basic structures, allowing for caffeine to act as a competitive antagonist of adenosine [33]. Therefore, it can increase the amount of calcium released from the endoplasmic reticulum by binding to and activating ryanodine receptors. Caffeine is quickly absorbed in the gastrointestinal tract and the highest blood concentration is found in around 30-60 minutes. We can find similar concentrations in the brain since it can cross the bloodbrain barrier due to its hydrophobic nature [34].

Chronic caffeine consumption reduces oxidative stress and ROS, inhibit lipid peroxidation and improve mitochondrial function. A study by Zhao et.al. 2019, showed that caffeine inhibits NLRP3 inflammasome activation by suppressing MAPK/NF-KB signalling and A2aR-associated ROS production [35]. Studies have linked caffeine consumption to the reduction of risk for developing metabolic diseases, for the specific case of the liver, caffeine relates to a decrease in enzyme elevations, reduce risk of fatty liver disease, cirrhosis, and nonalcoholic steatohepatitis [22]. Also, Coffee consumption seems to activate peroxiredoxin, which aids in $\mathrm{H}_{2} \mathrm{O} 2$ reduction and inhibition of JNK a key pathway involved in NASH. In addition, heat shock protein 70 (HSP70) and chaperone glucose-related protein 78 (GRP78) are also activated by coffee. These proteins help maintain endoplasmic reticulum homeostasis, as well as playing critical roles in anticancer defence through the adaptive immune system [4].

Molloy et al., showed that increased intake of coffee confers a significantly decreased risk of advanced fibrosis in patients with non-alcoholic steatohepatitis. This is also shown in rat models that is not just the action of caffeine but the coffee decreases the levels of liver fat. By giving decaffeinated coffee to rats with fatty liver disease shows lower levels of hepatic fat and collagen, reduced liver oxidative stress through glutathione metabolism, and liver inflammation [22].

Among other beneficial effects, caffeine can confer neuroprotection against the underlying dopaminergic neuronal degeneration and can influence the onset and progression of Parkinson's disease, amyotrophic lateral sclerosis due to the inhibition of adenosine receptors, and has shown to be effective in Huntington's disease because of its antioxidant capacity [36].

\section{Chlorogenic acid}

In coffee, an important component is chlorogenic acids. Depending on the roast, it is found in the range between 25 and $75 \mathrm{mg}$ per $100 \mathrm{~g}$, having the highest levels in low and medium roasted coffees [37]. Several Chlorogenic acids (CG-As) are powerful in-vitro antioxidants. They act as chemo-preventive agents by adjusting the expression of genes involved with enzyme expression for phase II metabolism. Phase II metabolism is an endogenous antioxidant pathway to convert reactive electrophile and xenobiotics into less toxic residues. Interestingly, researchers have associated phase II metabolism activity to cancer prevention [38, 39]. Chlorogenic acid (CGA) is a derivative of phenolic acid. Chemically, CGA 
(5-O-caffeoylquinic acid) is a cinnamate ester derived from caffeic acid and quinic acid [40], whose properties range from natural antioxidants to blood pressure regulators [41]. New research even suggests that CGA helps improve mood, lower blood sugar, reduce the spread of infections, and importantly induce hepatic protective and anti-fibrotic effects [18][42-44].

The liver is susceptible to several forms of damage either by drugs, alcohol consumption, trauma or viral disease which can eventually lead to fibrosis and disruption of proper architecture; characterized by stellar cell activation and ECM remodelling [17, 45]. Recently, Yang et al., confirmed the hepatoprotective effects of chlorogenic acid at a molecular level by regulation the miR-21/TGF- $\beta$ / Smad7 axis. This can imply that CGA can block effects of Smad2/3 effector of TGF- $\beta$ which signals MMP9 and CTGF, remodelling of ECM and promoting fibrosis [24]. Another recent study also showed that consumption of chlorogenic acid through activation of Nrf2 can lessen acetaminophen induced liver injury, which typically can lead to haemorrhage and necrosis. CGA helps infiltration of immune cells and elevates HSP60. This unsurprisingly led to the reduction of proinflammatory molecules COX2 and TNF- $\alpha$ and levels of AST/ALT [25]. The hepatoprotective effect is potentially due to the down regulation of $\mathrm{TLR} 3 / 4$ and NF-k 3 signalling pathways, this, in turn, could indicate that hepatoprotection relies heavily on its antioxidant effect inhibiting oxidative stress [46].

Some of the mechanism associated to CGA are antiinflammatory and antioxidant features. Recent studies have shown that CGA inhibits hepatic peroxisome proliferators activated receptor $\mathrm{Y}$ (PPAR $\mathrm{P}$ ) which prohibits liver steatosis; CGA scavenges ROS which reduces the expression of inflammation, resulting in low insulin resistance, fat accumulation, and body weight [ 46], as well as has hepatoprotective effects on lipopolysaccharidesinduced liver injury. Moreover, oxidative stress has been studied as an early biomarker to metabolic syndrome [47].

Interactions between Chlorogenic acids and other dietary components has been extensively investigated. An important interaction occurs with proteins, especially casein and albumin. When the chlorogenic acids are consumed with milk, 5-CQA and metabolites may interact with whey proteins such as $\beta$-lactoglobulin and with casein. These complexes may not be susceptible to proteolysis by gastrointestinal enzymes such as trypsin, chymotrypsin, pepsin and pancreatin, inhibiting the release of phenolic compounds from the protein complex and their absorption. This has been studied with coffee polyphenols, tea and cocoa polyphenols [48].

\section{Kahweol and cafestol}

kahweol and cafestol, coffee-specific diterpenes have shown anti-carcinogenic properties due to enzyme interaction involved in genotoxin metabolism (such as AFB1, phIp, dimethylbenz(a)anthracene (DMBA) and benzo(a)pyrene(BAP). It has been reported that diterpenes induce detoxifying enzymes such as glutathione S-transferase and UDP-glucuronosyltransferase (UGT) and inhibiting the activities of drug activating $\mathrm{p} 450$ isoenzymes [49].

Diterpenes antioxidant properties may lead to DNA protection, the induction of o6-methylguanine-DNAmethyl transferase, and inhibition of sulfotransferases and $\mathrm{N}$-acetyl-transferases reduces ROS formation and inhibit lipid peroxidation and inactivate superoxide radicals in vitro [50]. There is also evidence that kahweol and Cafestol inhibit the formation of 8-oxo-2' deoxyguanosine (8ohdG) in a mouse cell line [51]. The suppression of $\mathrm{CoX} 2$ and iNoS and the inhibition of NF$\mathrm{kb}$ may explain this effect according to Kim et.al. found in vitro experiments. There is also evidence about o6methylguanine-DNA methyltransferase (o6-MGMT), in experiments with rats, to remove o6-alkylguanine, a pro-carcinogenic enzyme which is caused by alkylating agents [52].

Even with the number of studies that has been published about DNA protection properties of coffee specific diterpenes (cafestol and kahweol), it is not to be expected to be relevant for humans. Serum levels of these specific diterpenes are still unknown and in-vitro experiments were conducted in animal cells at high concentration are not relevant for humans as the doses used in those experiments correspond to drink over 10 litres of coffee per day. It's not considered to be a good strategy to develop coffee brands with increased levels of these lipids to improve their chemoprotective properties, since it consumption has shown to cause hyperlipidaemia in rodents [53].

\section{Melanoidins}

Another important family of compounds are Melanoidins, a heterogenous group of polymers containing nitrogen which form during the last step of Maillard reaction and include in their backbone different constituents of green beans [54]. Melanoidins not only scavenge ROS but also activate Nrf2 and NF- k 3 . As a counterpart, the product of the Maillard reaction in coffee brewing causes inflammation associated with oxidative stress reactions, because of the formation of hydrogen peroxide [22, 23]. Also formed during the Maillard reaction process is $\mathrm{N}$-methylpyridinium, a derivative of the alkaloid trigonelline. This compound has been shown to produce a strong increase Glutathione S-transferases (GST) enzyme activity, which catalyses the detoxification of many genotoxic carcinogens, was observed in the liver. In addition, also increased levels of glucuronosyltransferase (UGT) [56]. 


\section{Summary of the properties of the bioactive compounds of coffee, can be seen in table 1.}

\begin{tabular}{|c|c|c|c|c|}
\hline \multicolumn{5}{|c|}{ Antioxidant effects of coffee } \\
\hline Compound & effect & In vivo & $\begin{array}{l}\text { In } \\
\text { vitro }\end{array}$ & bibliography \\
\hline \multirow{3}{*}{ Chlorogenic acids } & $\begin{array}{l}\text { Chlorogenic acids act as pro-oxidants at high concentrations, } \\
\text { while antioxidant properties were detected with doses which are } \\
\text { found in the blood of coffee drinkers }\end{array}$ & & $\mathrm{x}$ & Simic et al., 2007 \\
\hline & Decrease in oxidative stress & $\mathrm{x}$ & & Kim JY et al., 2004 \\
\hline & Inhibition of NF-kB (nuclear factor kappa B) pathway & $\mathrm{x}$ & & Zatorski et al., 2015 \\
\hline Caffeine & Induction of Nrf2 transcription factor & $\mathrm{x}$ & & Boettler et. At, 2011 \\
\hline \multirow{2}{*}{ Melanoidins } & Scavenge ROS & $\mathrm{x}$ & & Zatorski et al., 2015 \\
\hline & Activate Nrf2 and NF-kB & $\mathrm{x}$ & & Zatorski et al., 2015 \\
\hline \multirow{2}{*}{ N-Methylpyridinium } & Strong increase of the activity of GST enzyme & $\mathrm{x}$ & $\mathrm{x}$ & Somoza et al., 2003 \\
\hline & Increased levels of glucuronosyltransferase (UGT) & $\mathrm{x}$ & & Somoza et al., 2003 \\
\hline Diterpenoids & Inhibition of NFkB & & $\mathrm{x}$ & Kim JY et al., 2004 \\
\hline \multicolumn{5}{|c|}{ Anti-inflammatory effects of coffee } \\
\hline \multirow{4}{*}{ Chlorogenic acids } & Inhibiting prostaglandin e2 (PGe2) production & & $\mathrm{x}$ & Shan et al., 2009 \\
\hline & Reduce neutrophil infiltration & $\mathrm{x}$ & & Zatorski et al., 2015 \\
\hline & Suppression of pro-inflammatory cytokines & $\mathrm{x}$ & & Zatorski et al., 2015 \\
\hline & Inhibition of TnF - $\alpha$ in liver injury mice & $\mathrm{x}$ & & Xu et al., 2010 \\
\hline \multirow{3}{*}{ Caffeine } & Reduces the production of inflammation cytocines like IL-1B & $\mathrm{x}$ & & Fanf et al., 2019 \\
\hline & Increased serum levels of IL- 6 & $\mathrm{x}$ & & Walker et al., 2007 \\
\hline & Increased serum levels of IL-10 & $\mathrm{x}$ & & Tauler et al., 2013 \\
\hline \multirow{2}{*}{ Melanoidins } & $\begin{array}{l}\text { Reduced concentrations of proinflammatory cytokines such as } \\
\text { (TNF-a) and (IFN-g) }\end{array}$ & $\mathrm{x}$ & & $\begin{array}{l}\text { Vitaglione et al., } \\
2010\end{array}$ \\
\hline & Increase of anti-inflammatory ones such as IL- 4 & $\mathrm{x}$ & & $\begin{array}{l}\text { Vitaglione et al., } \\
2010\end{array}$ \\
\hline \multirow{2}{*}{ N-Methylpyridinium } & Reduces MCP-1 & & $\mathrm{x}$ & Digby et al., 2010 \\
\hline & Upregulates adiponectin in adipocytes infused with TNF-a & & $\mathrm{x}$ & Digby et al., 2010 \\
\hline Diterpenoids & Suppression of $\mathrm{CoX}_{2}$ and iNoS and inhibition NFkB & & $\mathrm{x}$ & Kim JY et al., 2004 \\
\hline \multicolumn{5}{|c|}{ Anti-proliferative effects of coffee } \\
\hline \multirow{2}{*}{ Chlorogenic acids } & Chemo-preventive phase II-enzymes via the Nrf2/ARe pathway & $\mathrm{x}$ & $\mathrm{x}$ & Volz et al., 2012 \\
\hline & Inhibition of DNA-methyltransferase & & $\mathrm{x}$ & Jurkowska et al., 2011 \\
\hline Caffeine & $\begin{array}{l}\text { Protective effects against different chemical carcinogens were } \\
\text { observed with low concentrations }\end{array}$ & & $\mathrm{x}$ & Sanyal et al., 1997 \\
\hline \multirow{2}{*}{ Melanoidins } & Inhibition of mitogen-activated protein kinase (MAPK) cascade & & $\mathrm{x}$ & Marko et al., 2003 \\
\hline & S and G2/M-phase cessation & & $\mathrm{x}$ & Kamei et al., 1997 \\
\hline \multirow{2}{*}{ N-Methylpyridinium } & Induces the chemo-preventive GST activity & $\mathrm{x}$ & & Huber et al., 2003 \\
\hline & Potent inducer of GST in human derived colon cells & & & Huber et al., 2003 \\
\hline \multirow{3}{*}{ Diterpenoids } & $\begin{array}{l}\text { Protect against DNA damage caused by genotoxic carcinogens } \\
\text { such as AFB1, phlp, DMBA and B[a]p }\end{array}$ & & $\mathrm{x}$ & Kim JY et al., 2004 \\
\hline & Prevent formation of DNA adducts by phlp in the colon & $\mathrm{x}$ & & Huber et al., 2003 \\
\hline & $\begin{array}{l}\text { Induction of o6-methylguanine-DNA methyltransferase } \\
\text { (o6-MGMT) in rats }\end{array}$ & $\mathrm{x}$ & & Huber et al., 2003 \\
\hline
\end{tabular}

Table 1: Principal activities of coffee and the molecular pathways affected 


\section{$\beta$-glucans}

$\beta$-glucans, are carbohydrates typically found in cell walls of bacteria, fungi, and plants including grains. These carbohydrates are a group of non-starch polysaccharides, composed of D-glucose monomers linked by $\beta$-glycosidic bonds. The macromolecular structure of $\beta$-glucans may vary depending on the isolation state and resources obtained. In addition, b-glucans can be divided upon by their digestibility in the gastrointestinal tract. Comprising the first group are non-structural carbohydrates, simple carbohydrates and non-fibrous polysaccharides; all easily hydrolyzed through enzymatic reactions and absorbed in the small intestine [57]. Next, a second group is resistant to enzymatic digestion in the small intestine, and requires bacteria to perform a fermentation process to digest these complex carbohydrates [58]. This fermentation capacity of $\beta$-glucans has also shown to have a lowering cholesterol impact by changing the concentrations of bile acids in the intestinal tract and promoting the production of shortchain fatty acids, which have a hypercholesterolemic effect [59]. $\beta$-glucans also increase intestinal viscosity and slow down glucose absorption rate, reduce postprandial insulin concentrations and reducing hepatic 5-hydroxy-3-methylglutaryl-coenzyme A (HMG-CoA) reductase activity and cholesterol synthesis stimulated by insulin [60]. The Food and Drug Administration (FDA) recommends since 1996 the consumptions of $0.75-3 \mathrm{~g}$ per day of oat and barley-derived $\beta$-glucan to achieve optimal health benefits. Recently, shown in individuals with type 2 diabetes, the consumption of bread enriched with oat $\beta$-glucans ( $3 \mathrm{~g} /$ day for 3 weeks) reduced by $5 \%$ total serum cholesterol and $10 \%$ of LDL cholesterol [61].

$\beta$-glucans found in grains are comprise by $\beta(1 \rightarrow 3 / 1 \rightarrow 4)$ bonds [59]. These highly polymerized $(1 \rightarrow 3) \beta$-glucans do not dissolve completely in water (polymerization (DP) $>100$ ) and are influenced by the composition of the side branches. Compared to other soluble and fermentable dietary fibers, $\beta$-glucans have more positive effects on health because of their capacity to create a high viscose solution at lower concentrations $(1 \%)$ and are stable with $\mathrm{pH}[59,62]$.

Studies reported that grains with the highest content of $\beta$-glucans ( $\mathrm{g} / 100 \mathrm{~g}$ dry weight) were barley (2-20 g; $65 \%$ soluble) and oats (3-8 g; $82 \%$ soluble) [63]. Grains largely found in Mexico and through Latin-America. In a meta-analysis researchers reviewed over 30 studies of oat and barley intake, showing positive effects in lipid profile, decreasing total cholesterol, LDL cholesterol, and triglyceride/triacylglycerol levels, $\beta$-glucans acted by activating $7 \alpha$-hydroxylase, causing cholesterol elimination from the body, and increase up-regulation of low-density lipoprotein receptor (LDLR) $[64,65]$. Another important aspect regulated by $\beta$-glucans is Insulin resistance, an important cause of hypertension. $\beta$-glucans modulate insulin metabolism and contributes to regulating blood pressure by decreasing plasma cholesterol levels also $\beta$-glucans associate with improvements in endothelial-originated vasodilatation, as increased body weight is a strong risk factor for hypertension [66].

Immuno-modulatory studies have shown that 1,3 $\beta$-glucans can enhance both humoral and cellular immunity [67]. In vivo studies in animals consuming of a variety of $\beta$-glucans on the responses to pathogen infections have shown increased microbial clearance and reduced mortality in lethally infected animals when they were exposed to $\beta$-glucans [68].

\section{Chitin glucans}

An interesting subpopulation of $\beta$-glucans are chitinglucans. In particular, chitin- $\beta-1,3$ glucan, a deacetylated form of chitin, chitosan, extracted from the fungal exoskeleton (Agaricus bisporus) counteracts some metabolic alterations occurring in diet-induced obese mice, such as increased fat mass, it modulates bacterial population in the colon, and increase the short-chain fatty acids concentrations in the colon [42]. One study completed in mice found that the effects of chronic consumption of chitin-glucan from a fungal source improved metabolic abnormalities induced by a highfat diet. Chitin-glucan decreased body weight gain, fat mass development, fasting hyperglycemia, glucose intolerance, hepatic triglyceride accumulation, and hypercholesterolemia, irrespective of caloric intake. We can attribute these beneficial effects to the restoration of the composition and/or activity of gut bacteria [71].

\section{Avenanthramide}

Another important family of compounds found in oats are avenanthramide. They are low molecular weight, soluble phenolic compounds [72]; made up from the conjugation of a phenylpropanoid with anthranilic acid or 5-hydroxy anthranilic acid, avenanthramides are produced by the plant itself in response to exposure to pathogens such as fungi [73]. Avenanthramides have shown strong antioxidant, oats antioxidant compounds include tocopherols, tocotrienols, phytic acid, and several types of phenolic compounds like avenanthramides, which are 1030 times better than other antioxidants such as vanillin and caffeic acid [74]. The antioxidant activity of the avenanthramides extracts has been tested in laboratory rats, supplementing their diets with avenanthramideenriched extract of oats at $100 \mathrm{mg} / \mathrm{kg}$, the results showed to increase superoxide dismutase (SOD) activity in skeletal muscle, liver, and kidneys, and to enhance glutathione peroxidase activity in heart and skeletal muscles [75].

At a cellular level, avenanthramides can interact with 
cellular components not only through their antioxidant activity but also through molecular and signaling pathways that are in charge of inflammation, showing inhibitory properties of vascular endothelial adhesion molecules like ICAM-1, VCAM-1, and E-selectin [72]. It has been reported that avenanthramides increase the production of Nitric Oxide (NO) and endothelial NO synthase expression by both endothelial cells and VSMC. The previous effect results in a reduction of blood pressure. The inhibitory effects of avenanthramides on VSMC added to the increase of NO production are substantial changes that potentially lend another CHD-related health benefit to oats, beyond their known effect of lowering blood cholesterol. Lastly, cell culture experiments have revealed that avenanthramides inhibit the proliferation of VSMCs their proliferation is well known to be a determining factor in the development of atherosclerosis and restenosis after angioplasty [76]. Summary of the properties of the bioactive compounds of oats can be found in table 2 .

\begin{tabular}{|c|c|c|c|c|}
\hline \multicolumn{5}{|c|}{ Antioxidant effects of Cereals } \\
\hline Compound & Effect & In vivo & In vitro & Bibliography \\
\hline B-Glucan & Hydroxyl radical scavenging activity & & $\mathrm{x}$ & Kofuji et al., 2012 \\
\hline \multirow{2}{*}{ Avenanthramides } & $\begin{array}{l}\text { Increase superoxide dismutase (SOD) activity in } \\
\text { skeletal muscle, liver, and kidneys }\end{array}$ & $\mathrm{x}$ & & Ji et al., 2003 \\
\hline & $\begin{array}{l}\text { Enhance glutathione peroxidase activity in heart } \\
\text { and skeletal muscles }\end{array}$ & $\mathrm{x}$ & & Ji et al., 2003 \\
\hline \multicolumn{5}{|c|}{ Anti-inflammatory effects of Cereals } \\
\hline \multirow{2}{*}{ B-Glucan } & $\begin{array}{l}\text { Diminution of inflammatory cytocines like IL 1-B, } \\
\text { IL } 10 \text { serum levels }\end{array}$ & $\mathrm{x}$ & & Luo et al., 2019 \\
\hline & Diminution of TNF a serum levels & $\mathrm{x}$ & & Luo et al., 2019 \\
\hline \multirow{2}{*}{ Avenanthramides } & $\begin{array}{l}\text { Inhibition of vascular endothelial cell expression } \\
\text { of adhesion molecules, including ICAM-1, VCAM-1, } \\
\text { and E-selectin }\end{array}$ & & $\mathrm{x}$ & Liu et al., 2004 \\
\hline & $\begin{array}{l}\text { Reducing the production of several inflammatory } \\
\text { cytokines and chemokines, including IL-6, IL-8, } \\
\text { and MCP-1 }\end{array}$ & & $\mathrm{x}$ & Liu et al., 2004 \\
\hline \multicolumn{5}{|c|}{ Anti-Proliferative effects of Cereals } \\
\hline B-Glucan & Increases macrophages viability & & $\mathrm{x}$ & $\begin{array}{l}\text { Choromanska et al., } \\
2015\end{array}$ \\
\hline \multirow{6}{*}{ Avenanthramides } & Inhibition of VSMC proliferation & & $\mathrm{x}$ & Nie at al., 2006 \\
\hline & $\begin{array}{l}\text { Modulation of cell cycles regulatory proteins such } \\
\text { as p53, p21cip1, p27kip1, cyclin-D1, and pRb }\end{array}$ & & $\mathrm{x}$ & Nie at al., 2006 \\
\hline & $\begin{array}{l}\text { Inhibits cell cycle signaling at the G1 to S phase } \\
\text { transition }\end{array}$ & & $\mathrm{x}$ & Nie at al., 2006 \\
\hline & Suppress phosphorylation of pRb & & $\mathrm{x}$ & Nie at al., 2006 \\
\hline & $\begin{array}{l}\text { Decrease cyclin D1 expression and an increase in } \\
\text { cyclin-dependent kinase inhibitor p21cip1 expres- } \\
\text { sion }\end{array}$ & & $\mathrm{x}$ & Nie at al., 2006 \\
\hline & $\begin{array}{l}\text { Increased the expression level and stability of p } 53 \\
\text { protein }\end{array}$ & & $\mathrm{x}$ & Nie at al., 2006 \\
\hline
\end{tabular}

Table 2: Principal activities of cereals and the molecular pathways affected 


\section{Conclusion}

Breakfast is an important meal that people often underestimate, in this article, we have addressed the bioactive compounds of two foods with easy access and safety for the population (coffee and oats), which, according to the data collected, can provide the nutritional energy, and the prevention of degenerative injuries to the liver because of the synergism presented by the bioactive compounds that are present in each of these foods and that could healthily cover the energy requirements. Therefore, foods with high nutritional potential need to be included in the daily selection of foods, especially during the start of daily activities.

Being the liver the most metabolically active organ which maintains itself in a complex environment of different concentrations that changes the cellular environment, with products from themetabolic reactions of the organism that come mostly from the daily diet, it's recommendable to consume foods with anti-inflammatory compounds and antioxidants, among others, helps in the maintenance and the regeneration of cellular levels of reduced glutathione with low levels of ROS, reduce inflammatory cytokines and prostaglandins in serum, inhibits cell expression of adhesion molecules and the Induction of o6-methylguanine-DNA methyltransferase (o6-MGMT), as a result, a diminution in the incidence of proliferative (such as cancer), inflammatory and metabolic diseases (diabetes) is evidenced.

Author Contributions: Research and writingAJG-J, ZG-B, JFI; Conceptualization and supervision- JFI, JLD-G

Funding: This research received no external funding.

Acknowledgments: Collaboration of all authors.

Conflicts of Interest: The authors declare no conflict of interest.

\section{References}

1. Rampersaud GC, Pereira MA, Girard BL, Adams J, Metzl JD. Breakfast habits, nutritional status, body weight, and academic performance in children and adolescents. J Am Diet Assoc. 2005;105(5):743760. doi:10.1016/j.jada.2005.02.007

2. González-Ponce HA, Rincón-Sánchez AR, Jaramillo-Juárez F, Moshage $\mathrm{H}$. Natural dietary pigments: Potential mediators against hepatic damage induced by over-the-counter non-steroidal anti-inflammatory and analgesic drugs. Nutrients.
2018;10(2):1-39. doi:10.3390/nu10020117

3. Kamada I, Truman L, Bold J, Mortimore D. The impact of breakfast in metabolic and digestive health. Gastroenterol Hepatol from Bed to Bench. 2011;4(2):76-85. doi:10.22037/ghfbb.v4i2.127

4. Morisco F, Lembo V, Mazzone G, Camera S, Caporaso N. Coffee and liver health. J Clin Gastroenterol. 2014;48(December):S87-S90. doi:10.1097/ MCG.0000000000000240

5. Buckner SL, Loprinzi PD, Loenneke JP. Letters to the Editor. Am J Clin Nutr. Published online 2016:4. doi:10.32380/alrj.v0i0.829

6. Welfens PJJ. Macroeconomic and health care aspects of the coronavirus epidemic : EU, US and global perspectives. Int Econ Econ Policy. Published online 2020:1-68.

7. Davies S. Pandemics and the consequences of COVID-19. Econ Aff. 2020;40(2):131-137. doi:10.1111/ecaf.12415

8. Ramos-Tovar E, Muriel P. Does Nutrition Matter in Liver Disease? Elsevier Inc.; 2017. doi:10.1016/ B978-0-12-804274-8.00053-9

9. Mendez-Sanchez N, Villa AR, Chavez-Tapia NC, et al. Trends in liver disease prevalence in Mexico. Ann Hepatol. 2005;4(1):52-55.

10. Bastien M, Poirier P, Lemieux I, Després JP. Overview of epidemiology and contribution of obesity to cardiovascular disease. Prog Cardiovasc Dis. 2014;56(4):369-381. doi:10.1016/j. pcad.2013.10.016

11. Boles A, Kandimalla R, Reddy PH. Dynamics of diabetes and obesity: Epidemiological perspective. Biochim Biophys Acta - Mol Basis Dis. 2017;1863(5):1026-1036. doi:10.1016/j.bbadis.2017.01.016

12. Singh AK, Raj V, Keshari AK, et al. Isolated mangiferin and naringenin exert antidiabetic effect via PPAR $\gamma /$ GLUT4 dual agonistic action with strong metabolic regulation. Chem Biol Interact. 2018;280(September 2017):33-44. doi:10.1016/j. cbi.2017.12.007

13. Asrani SK, Devarbhavi H, Eaton J, Kama- 
th PS. Burden of liver diseases in the world. J Hepatol. 2019;70(1):151-171. doi:10.1016/j. jhep.2018.09.014

14. Morisco F, Vitaglione P, Amoruso D, Russo B, Fogliano V, Caporaso N. Foods and liver health. Mol Aspects Med. 2008;29(1-2):144-150. doi:10.1016/j.mam.2007.09.003

15. Asrani SK, Devarbhavi H, Eaton J, Kamath PS. Burden of liver diseases in the world. J Hepatol. 2018;6(14):226-241. doi:10.1007/s11888-018$0420-y$

16. Guy J, Peters MG. Liver disease in women: The influence of gender on epidemiology, natural history, and patient outcomes. Gastroenterol Hepatol. 2013;9(10):633-639.

17. Roehlen N, Crouchet E, Baumen TE. Liver Fibrosis : Mechanistic Concepts and. cells. 2020;(9):143. doi:doi:10.3390/cells9040875

18. Arauz J, Ramos-Tovar E, Muriel P. Coffee and the Liver. Elsevier Inc.; 2017. doi:10.1016/B978-0-12804274-8.00048-5

19. Poltavets V, Kochetkova M, Pitson SM, Samuel MS. The role of the extracellular matrix and its molecular and cellular regulators in cancer cell plasticity. Front Oncol. 2018;8(OCT):1-19. doi:10.3389/fonc.2018.00431

20. Bataller R, Brenner D. Liver Fibrosis. J Clin Invest. 2005;1115(2):2009-2218. doi:10.1172/ JCI200524282.The

21. Esposito F, Morisco F, Verde V, et al. Moderate coffee consumption increases plasma glutathione but not homocysteine in healthy subjects. Aliment Pharmacol Ther. 2003;17(4):595-601. doi:10.1046/j.1365-2036.2003.01429.x

22. Molloy JW, Calcagno CJ, Williams CD, Jones FJ, Torres DM, Harrison SA. Association of coffee and caffeine consumption with fatty liver disease, nonalcoholic steatohepatitis, and degree of hepatic fibrosis. Hepatology. 2012;55(2):429-436. doi:10.1002/hep. 24731

23. Kim JY, Jung KS, Lee KJ, et al. The coffee diterpene kahweol suppress the inducible nitric oxi- de synthase expression in macrophages. Cancer Lett. 2004;213(2):147-154. doi:10.1016/J.CANLET.2004.04.002

24. Yang F, Luo L, Zhu Z De, et al. Chlorogenic acid inhibits liver fibrosis by blocking the miR-21-regulated TGF- $\beta 1 /$ Smad7 signaling pathway in vitro and in vivo. Front Pharmacol. 2017;8(DEC):113. doi:10.3389/fphar.2017.00929

25. Hu F, Guo Q, Wei M, et al. Chlorogenic acid alleviates acetaminophen-induced liver injury in mice via regulating Nrf2-mediated HSP60-initiated liver inflammation. Eur J Pharmacol. 2020;883:173286. doi:10.1016/j.ejphar.2020.173286

26. Bae M, Park YK, Lee JY. Food components with antifibrotic activity and implications in prevention of liver disease. J Nutr Biochem. 2018;55:111. doi:10.1016/j.jnutbio.2017.11.003

27. López-Méndez LF, Meléndez-Coral M, Cerda-Flores RM, et al. Standardization and Glycemic Index of a Traditional Oat ( Avena sativa ) Beverage. J Food Nutr Res. 2016;4(6):388-393. doi:10.12691/jfnr-4-6-7

28. Kelloggs JH. The Living Temple (1903). (Andesite, ed.). CreateSpace Independent Publishing Platform; 2014.

29. El Ouaamari A, Minehira K. Nonalcoholic fatty liver disease: Its mechanisms and complications. Int J Endocrinol. 2013;2013:2-3. doi:10.1155/2013/969748

30. Arroyo P, Loria A, Méndez O. Changes in the household calorie supply during the 1994 economic crisis in Mexico and its implications on the obesity epidemic. Nutr Rev. 2004;62(7 II):163168. doi:10.1111/j.1753-4887.2004.tb00088.x

31. Karmally W, Montez MG, Palmas W, et al. Cholesterol-Lowering Benefits of Oat-Containing Cereal in Hispanic Americans. J Am Diet Assoc. 2005;105(6):967-970. doi:10.1016/j. jada.2005.03.006

32. Fox GP, Wu A, Yiran L, Force L. Variation in caffeine concentration in single coffee beans. J Agric Food Chem. 2013;61(45):10772-10778. doi:10.1021/jf4011388 
33. Chee HK, Oh SJ. Molecular Vibration-Activity Relationship in the Agonism of Adenosine Receptors. Genomics Inform. 2013;11(4):282. doi:10.5808/gi.2013.11.4.282

34. Dobson KL, Jackson C, Balakrishnan S, Bellamy TC. Caffeine modulates vesicle release and recovery at cerebellar parallel fibre terminals, independently of calcium and cyclic AMP signalling. PLoS One. 2015;10(5):1-23. doi:10.1371/journal. pone. 0125974

35. Zhao W, Ma L, Cai C, Gong X. Caffeine inhibits NLRP3 inflammasome activation by suppressing MAPK/NF- $\kappa \mathrm{B}$ and A2aR signaling in LPS-induced THP-1 macrophages. Int J Biol Sci. 2019;15(8):1571-1581. doi:10.7150/ijbs.34211

36. Kolahdouzan M, Hamadeh MJ. The neuroprotective effects of caffeine in neurodegenerative diseases. CNS Neurosci Ther. 2017;23(4):272-290. doi:10.1111/cns. 12684

37. International Agency for Research on Cancer. IARC Monographs on the Identification of Carcinogenic Hazards to Humans. Vol 51. fist. World Health Organization; 1991.

38. Ramos S. Cancer chemoprevention and chemotherapy: Dietary polyphenols and signalling pathways. Mol Nutr Food Res. 2008;52(5):507-526. doi:10.1002/mnfr.200700326

39. Feng R, Lu Y, Bowman LL, Qian Y, Castranova V, Ding M. Inhibition of activator protein-1, NF$\kappa \mathrm{B}$, and MAPKs and induction of phase 2 detoxifying enzyme activity by chlorogenic acid. J Biol Chem. 2005;280(30):27888-27895. doi:10.1074/ jbc.M503347200

40. Wang GF, Shi LP, Ren YD, et al. Anti-hepatitis $B$ virus activity of chlorogenic acid, quinic acid and caffeic acid in vivo and in vitro. Antiviral Res. 2009;83(2):186-190. doi:10.1016/j.antiviral.2009.05.002

41. Meng S, Cao J, Feng Q, Peng J, Hu Y. Roles of chlorogenic Acid on regulating glucose and lipids metabolism: a review. Evidence-Based Complement Altern Med. 2013;2013:1-11.

42. Utsunomiya $\mathrm{H}$, Ichinose $\mathrm{M}$, Uozaki $\mathrm{M}$, Tsuji- moto K, Yamasaki H, Koyama AH. Antiviral activities of coffee extracts in vitro. Food Chem Toxicol. 2008;46(6):1919-1924. doi:10.1016/J. FCT.2008.01.031

43. Li X, Liu Y, Hou X, et al. Chlorogenic Acid Inhibits the Replication and Viability of Enterovirus 71 In Vitro. PLoS One. 2013;8(9):1-10. doi:10.1371/ journal.pone.0076007

44. Simon C, Herling AW, Preibisch G, Burger H-J. Upregulation of Hepatic Glucose 6-Phosphatase Gene Expression in Rats Treated with an Inhibitor of Glucose-6-phosphate Translocase. Arch Biochem Biophys. 2000;373(2):418-428. doi:10.1006/ ABBI.1999.1560

45. Hernández-Aquino E, Muriel P. Beneficial effects of naringenin in liver diseases: Molecular mechanisms. World J Gastroenterol. 2018;24(16):16791707. doi:10.3748/wjg.v24.i16.1679

46. Naveed M, Hejazi V, Abbas M, et al. Chlorogenic acid (CGA): A pharmacological review and call for further research. Biomed Pharmacother. 2018;97(August 2017):67-74. doi:10.1016/j.biopha.2017.10.064

47. Xu Y, Chen J, Yu X, et al. Protective effects of chlorogenic acid on acute hepatotoxicity induced by lipopolysaccharide in mice. Inflamm Res. 2010;59(10):871-877. doi:10.1007/s00011-010$0199-\mathrm{z}$

48. Rawel HM, Kroll J, Hohl UC. Model studies on reactions of plant phenols with whey proteins. Nahrung - Food. 2001;45(2):72-81. doi:10.1002/1521-3803(20010401)45:2<72::AID-FOOD72>3.0.CO;2-U

49. Cavin C, Holzhaeuser D, Scharf G, Constable A, Huber WW, Schilter B. Cafestol and kahweol, two coffee specific diterpenes with anticarcinogenic activity. Food Chem Toxicol. 2002;40(8):11551163. doi:10.1016/S0278-6915(02)00029-7

50. Huber WW, Parzefall W. Modification of N-acetyltransferases and glutathione S-transferases by coffee components: Possible relevance for cancer risk. Methods Enzymol. 2005;401:307-341. doi:10.1016/S0076-6879(05)01020-7 
51. Lee KJ, Jeong HG. Protective effects of kahweol and cafestol against hydrogen peroxide-induced oxidative stress and DNA damage. Toxicol Lett. 2007;173(2):80-87. doi:10.1016/j.toxlet.2007.06.008

52. Huber WW, Scharf G, Nagel G, Prustomersky S, Schulte-Hermann R, Kaina B. Coffee and its chemopreventive components Kahweol and Cafestol increase the activity of O6-methylguanine-DNA methyltransferase in rat liver-comparison with phase II xenobiotic metabolism. Mutat Res Mol Mech Mutagen. 2003;522(1-2):57-68. doi:10.1016/ S0027-5107(02)00264-6

53. Urgert R, Essed N, Van der Weg G, Kosmeijer-Schuil TG, Katan MB. Separate effects of the coffee diterpenes cafestol and kahweol on serum lipids and liver aminotransferases. Am J Clin Nutr. 1997;65(2):519-524. doi:10.1093/ajcn/65.2.519

54. Rufián-Henares JA, Pastoriza S. Coffee in Health and Disease Prevention. In: Preedy VR, ed. Coffee in Health and Disease Prevention. Academic Press; 2015:853-858. doi:10.1016/B978-0-12409517-5.00094-2

55. Liu Y, Kitts DD. Confirmation that the Maillard reaction is the principle contributor to the antioxidant capacity of coffee brews. Food Res Int. 2011;44(8):2418-2424. doi:10.1016/J.FOODRES.2010.12.037

56. Somoza V, Lindenmeier M, Wenzel E, Frank O, Erbersdobler HF, Hofmann T. Activity-Guided Identification of a Chemopreventive Compound in Coffee Beverage Using in Vitro and in Vivo Techniques. J Agric Food Chem. 2003;51(23):68616869. doi:10.1021/jf034750e

57. Zeković DB, Kwiatkowski S, Vrvić MM, Jakovljević D, Moran CA. Natural and Modified $(1 \rightarrow 3)-\beta-D$ Glucans in Health Promotion and Disease Alleviation. Crit Rev Biotechnol. 2005;25(4):205-230. doi:10.1080/07388550500376166

58. Bozbulut R, Sanlier N. Promising effects of $\beta$-glucans on glyceamic control in diabetes. Trends Food Sci Technol. 2019;83(November 2018):159166. doi:10.1016/j.tifs.2018.11.018

59. Chen J, Raymond K. Beta-glucans in the treat- ment of diabetes and associated cardiovascular risks. Vasc Health Risk Manag. 2008;4(6):12651272. doi:10.2147/vhrm.s3803

60. Daou C, Zhang H. Oat Beta-Glucan: Its Role in Health Promotion and Prevention of Diseases. Compr Rev Food Sci Food Saf. 2012;11(4):355365. doi:10.1111/j.1541-4337.2012.00189.x

61. Liatis S, Tsapogas P, Chala E, et al. The consumption of bread enriched with betaglucan reduces LDL-cholesterol and improves insulin resistance in patients with type 2 diabetes. Diabetes Metab. 2009;35(2):115-120. doi:10.1016/J.DIABET.2008.09.004

62. Theuwissen E, Mensink RP. Water-soluble dietary fibers and cardiovascular disease. Physiol Behav. 2008;94(2):285-292. doi:10.1016/j.physbeh.2008.01.001

63. El Khoury D, Cuda C, Luhovyy BL, Anderson GH. Beta glucan: Health benefits in obesity and metabolic syndrome. J Nutr Metab. 2012;2012. doi: $10.1155 / 2012 / 851362$

64. Nilsson LM, Abrahamsson A, Sahlin S, et al. Bile acids and lipoprotein metabolism: Effects of cholestyramine and chenodeoxycholic acid on human hepatic mRNA expression. Biochem Biophys Res Commun. 2007;357(3):707-711. doi:10.1016/j. bbrc.2007.03.196

65. Tiwari U, Cummins E. Meta-analysis of the effect of $\beta$-glucan intake on blood cholesterol and glucose levels. Nutrition. 2011;27(10):1008-1016. doi:10.1016/J.NUT.2010.11.006

66. Ferri C, Bellini C, Desideri G, et al. Relationship between insulin resistance and nonmodulating hypertension: linkage of metabolic abnormalities and cardiovascular risk. Diabetes. 1999;48(8):1623 LP - 1630. doi:10.2337/diabetes.48.8.1623

67. Vetvicka V, Dvorak B, Vetvickova J, et al. Orally administered marine $(1 \rightarrow 3)$ - $\beta$-d-glucan Phycarine stimulates both humoral and cellular immunity. Int J Biol Macromol. 2007;40(4):291-298. doi:10.1016/j.ijbiomac.2006.08.009

68. Hetland G, Ohno N, Aaberge IS, Løvik M. Protective effect of $\beta$-glucan against systemic Strep- 
tococcus pneumoniae infection in mice. FEMS Immunol Med Microbiol. 2000;27(2):111-116. doi:10.1016/S0928-8244(99)00172-8

69. Šim\runek J, Tishchenko G, Hodrová B, Barto\ vnová $\mathrm{H}$. Effect of chitosan on the growth of human colonic bacteria. Folia Microbiol (Praha). 2006;51(4):306-308. doi:10.1007/BF02931820

70. Neyrinck AM, Bindels LB, De Backer F, Pachikian BD, Cani PD, Delzenne NM. Dietary supplementation with chitosan derived from mushrooms changes adipocytokine profile in diet-induced obese mice, a phenomenon linked to its lipid-lowering action. Int Immunopharmacol. 2009;9(6):767773. doi:10.1016/j.intimp.2009.02.015

71. Neyrinck AM, Possemiers S, Verstraete W, De Backer F, Cani PD, Delzenne NM. Dietary modulation of clostridial cluster XIVa gut bacteria (Roseburia spp.) by chitin-glucan fiber improves host metabolic alterations induced by high-fat diet in mice. J Nutr Biochem. 2012;23(1):51-59. doi:10.1016/j.jnutbio.2010.10.008

72. Liu L, Zubik L, Collins FW, Marko M, Meydani M. The antiatherogenic potential of oat phenolic compounds. Atherosclerosis. 2004;175(1):39-49. doi:10.1016/j.atherosclerosis.2004.01.044

73. Matsukawa $\mathrm{T}$, Isobe $\mathrm{T}$, Ishihara $\mathrm{A}$, Iwamura $\mathrm{H}$. Occurrence of avenanthramides and hydroxycinnamoyl-CoA:hydroxyanthranilate N-hydroxycinnamoyltransferase activity in oat seeds. Zeitschrift fur Naturforsch - Sect C J Biosci. 2000;55(1-2):3036. doi:10.1515/znc-2000-1-207

74. Dimberg LH, Theander O, Lingnert H. Avenanthramides. A Group of Phenolic Antioxidants in Oats. Am Assoc Cereal Chem. 1993;70(6):637641.

75. Ji LL, Lay D, Chung E, Fu Y, Peterson DM. Effects of avenanthramides on oxidant generation and antioxidant enzyme activity in exercised rats. Nutr Res. 2003;23(11):1579-1590. doi:10.1016/ S0271-5317(03)00165-9

76. Nie L, Wise ML, Peterson DM, Meydani M. Avenanthramide, a polyphenol from oats, inhibits vascular smooth muscle cell proliferation and enhances nitric oxide production. Atherosclerosis. 2006;186(2):260-266. doi:10.1016/j.atherosclerosis.2005.07.027

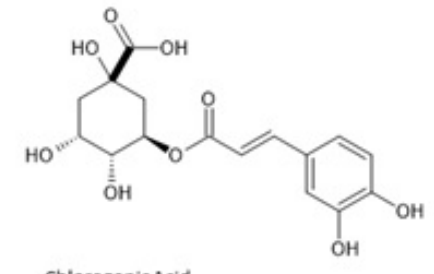

Chlorogenic Acid

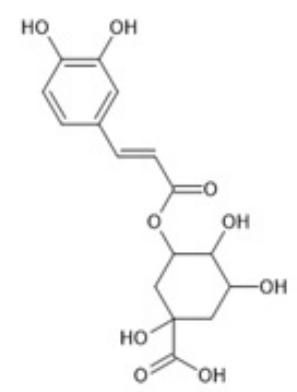

Melanoidins
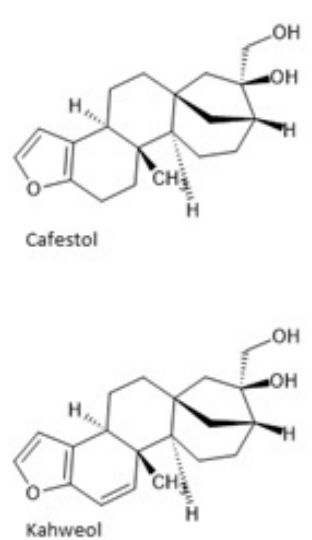
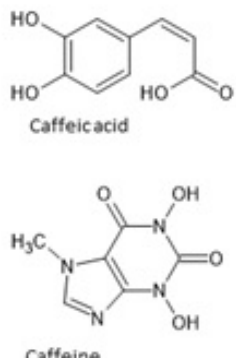

Caffeine
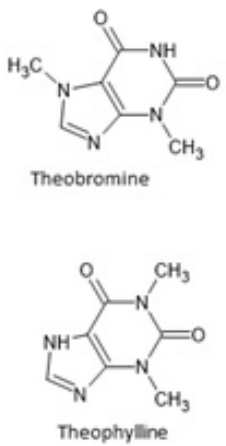

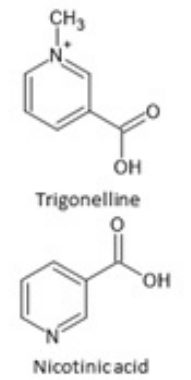

